\title{
SPEI-Based Spatiotemporal Analysis of Drought in Haihe River Basin from 1961 to 2010
}

\author{
Meijian Yang, ${ }^{1,2}$ Denghua Yan,,2 Yingdong Yu, ${ }^{1,2}$ and Zhiyong Yang ${ }^{1,2}$ \\ ${ }^{1}$ State Key Laboratory of Simulation and Regulation of Water Cycle in River Basin, China Institute of Water Resources and \\ Hydropower Research (IWHR), Beijing 100038, China \\ ${ }^{2}$ Water Resources Department, China Institute of Water Resources and Hydropower Research (IWHR), Beijing 100038, China \\ Correspondence should be addressed to Zhiyong Yang; yangzy@iwhr.com
}

Received 10 September 2015; Accepted 24 November 2015

Academic Editor: Jorge E. Gonzalez

Copyright (C) 2016 Meijian Yang et al. This is an open access article distributed under the Creative Commons Attribution License, which permits unrestricted use, distribution, and reproduction in any medium, provided the original work is properly cited.

Under the background of climate change, the monthly accumulated precipitation and monthly averaged temperature of 47 meteorological stations in and around Haihe River Basin (HRB) were analyzed using Standardized Precipitation Evapotranspiration Indices (SPEI) to obtain the temporal variability and spatial distribution of different drought levels during the last 50 years with the support of GIS. The results show that (1) from 1961 to 2010 the drought frequency and degree in annual and seasonal scale are rising and the affecting areas of all degrees of drought have a temporal variability of increasing trend. The ratios that the influencing area of drought, light drought, moderate drought, severe drought, and extreme drought account for the whole HRB area are increasing with gradients of $0.64 \% / a, 0.18 \% / a, 0.31 \% / a, 0.14 \% / a$, and $0.01 \% / a$, respectively, and (2) there is a climate break point which occurred in 1990; after the comparison of the drought happening probability between 1961 and 1990 and between 1991 and 2010, all degrees of drought occurrence probability have a remarkable rising trend, and the drought concentrating regions moved from the north HRB to the central HRB.

\section{Introduction}

Drought is one of the main natural disasters which affects the agricultural productivity and socioeconomic development. Haihe River Basin (HRB) acts as the center of society, economy, and culture as well as being one of the three most important granaries in China, suffering the most serious drought disasters compared with any other places. Therefore, to figure out the spatiotemporal variability of different drought degrees in HRB is becoming increasingly crucial not only for the improvement of the local social economy but also for enhancing the evolution of ecological environment. Many researchers have done a plenty of works in studying drought in HRB. Chu et al. studied the spatial and temporal variability of daily precipitation in $\mathrm{HRB}$ that shows the precipitation of 1958-2007 has been decreasing except for spring season [1]. Dong and Liu used the drought entropy and evidential reasoning algorithm in a case study of the Haihe River Basin to assess water security risks during drought periods [2].
Recently, the meteorological drought indexes used by researchers to analyze the spatiotemporal drought variability mainly include the Precipitation Percentile Index (PDECI), Z Index, Standardized Precipitation Index (SPI), Compound Index (CI), and Palmer Drought Severity Index (PDSI). Among the indexes above, the SPI and PDSI were used most widely and profoundly [3-5]. Bonaccorso et al. used SPI as a method to estimate the drought occurrence in Sicily which suggests that the entire island is characterized by a drought variability with multiyear fluctuations and a tendency towards drier periods from the seventies onward [6]. Tsakiris and Vangelis used SPI to support a Drought Watch System for an area of mesoscale dimensions [7]. Li et al. developed the drought reconstruction by calibrating tree-ring data with PDSI [8]. However, SPI cannot reflect how the rising temperature (the main character of global climate change) influences the drought variability; PDSI is not good at demonstrating the short-term drought and it only works well in arid and semiarid regions. To tackle the drawbacks of the indexes above, 
the Standardized Precipitation Evapotranspiration Indices (SPEI) were put forward by Vicente-Serrano as a combination of the advantages of SPI and PDSI, which takes the response of drought to evapotranspiration as well as the spatial consistency and multiple temporal scales into consideration with a main character of easy calculation [9-11]. Frequently used by researchers in dissecting the spatiotemporal features and changing tendency in a plenty of different regions, SPEI was verified to be good at detecting the drought trend under the background of global climate change [12-16].

This paper, based on the daily precipitation and temperature data for 50 years and the support of GIS, systematically analyzed the temporal trend and spatial distribution of different degrees of drought in HRB combining SPEI with $\mathrm{M}-\mathrm{K}$ method to provide a scientific suggestion to the relief of drought catastrophe and to help in promoting the optimal allocation of water resources.

\section{Overview of Study Area}

Haihe River Basin, one of the seven river basins in China, located in the west of Bohai Sea, between $112^{\circ} \mathrm{E} \sim 120^{\circ} \mathrm{E}$ and $35^{\circ} \mathrm{N} \sim 43^{\circ} \mathrm{N}$, crosses eight provinces including entire Beijing and Tianjin, the most part of Hebei province, small part of Shanxi province, Henan province, Liaoning province, Shandong province, and the Inner Mongolia Autonomous Region [17]. The terrain consists of three types, including plateau, mountain, and plain, with elevation rising from southeast to northwest. The total area of HRB is $317,800 \mathrm{~km}^{2}$, in which mountain area occupies $189,000 \mathrm{~km}^{2}, 59.5$ percent of the total area, and the rest $129,000 \mathrm{~km}^{2}$ is the flat area, accounting for 40.5 percent of the total area (Figure 1).

The major climate of HRB is the warm and semihumid continental monsoon climate with a main character of cold and dry winter and hot and humid summer. The annual accumulated rainfall and annual temperature of HRB averaged over 50 years from 1961 to 2010 are $521 \mathrm{~mm}$ and $10.2^{\circ} \mathrm{C}$, separately. The dropping precipitation and rising temperature in HRB contribute to the decrease of river runoffs and the increasing frequency and heightening degree of drought [18]. Being the social, economic, and political center as well as being an important granary of China, HRB is the core area with high priority of safety insurance. However, the severe and continuous drought makes HRB one of the most calamitous and vulnerable areas in China.

\section{Data and Methods}

3.1. Data Sources. The daily precipitation and temperature data from 1961 to 2010 in the selected 47 meteorological stations in and around HRB with comparative complete dataset are obtained from China Meteorological Data Sharing Service System. The missing values in each station were filled with the average values of the nearest 5 stations.

3.2. SPEI. The principle of SPEI is using the degree of the difference between precipitation and evapotranspiration which

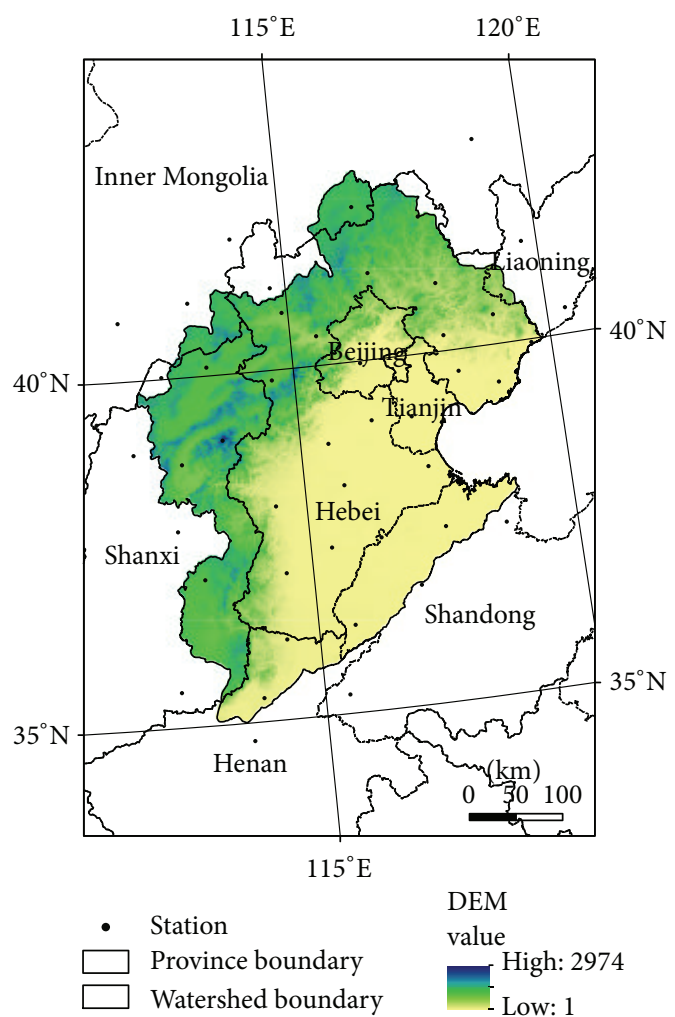

FIgURE 1: The geological location of HRB and Digital Elevation Model (DEM).

deviates the average status to represent the regional drought $[19,20]$. The calculation steps are as follows.

Thornthwaite method, one of the most widely used methods in calculating the potential evapotranspiration (PET), which takes the monthly mean temperature and monthly mean sunshine hour as the key factors, was used based on the following formula [21]:

$$
\mathrm{PET}=16 \times\left(\frac{N}{12}\right) \times\left(\frac{m}{30}\right) \times\left(10 \times \frac{T_{i}}{I}\right)^{a},
$$

where $N$ is the monthly mean sunshine hour, $m$ is the number of days in a month, $T_{i}$ is the monthly mean temperature, $a$ is given as formula (2), and $I$ is a cumulative number of 12month thermal indexes calculated as formula (3):

$$
\begin{aligned}
a= & 6.75 \times 10^{-7} \times I^{3}-7.71 \times 10^{-5} \times I^{2}+1.79 \times 10^{-2} \\
& \times I+0.49, \\
I= & \sum_{i=1}^{12}\left(\frac{T_{i}}{5}\right)^{1.514} .
\end{aligned}
$$

The difference between accumulated monthly precipitation and evapotranspiration was calculated as follows:

$$
D_{i}=P_{i}-\mathrm{PET}_{i}
$$

where $D_{i}$ is the difference between precipitation and potential evapotranspiration, $P_{i}$ is the monthly precipitation, and $\mathrm{PET}_{i}$ is the monthly potential evapotranspiration. 
TABLE 1: Classification standard of drought based on SPEI.

\begin{tabular}{lcccc}
\hline No drought & Light drought & Moderate drought & Severe drought & Extreme drought \\
\hline$-0.5<$ SPEI & $-1<$ SPEI $\leq-0.5$ & $-1.5<$ SPEI $\leq-1$ & $-2<$ SPEI $\leq-1.5$ & SPEI $\leq-2$ \\
\hline
\end{tabular}

The accumulated water profit or loss series with meteorology meaning in different time scales were constructed using the following formula:

$$
D_{n}^{k}=\sum_{i=0}^{k-1}\left(P_{n-i}-\operatorname{PET}_{n-i}\right), \quad n \geq k
$$

where $k$ is the time scale (month) and $n$ is the calculation frequency.

Other than SPI that could be calculated with twoparameter distribution (e.g., gamma distribution), a threeparameter distribution is needed to calculate the SPEI. Vicente-Serrano found the log-logistic distribution correlates best to the $D$ series compared with other three selected threeparameter distributions (Pearson III, lognormal, and general extreme values). Therefore, log-logistic probability density function was used to fit the sequence as follows:

$$
f(x)=\frac{\beta}{\alpha}\left(\frac{x-\gamma}{\alpha}\right)^{\beta-1}\left[1+\left(\frac{x-\gamma}{\alpha}\right)^{\beta}\right]^{-2},
$$

where $\alpha, \beta$, and $\gamma$ are scale, shape, and origin parameters, separately, which are obtained using the $L$-moment procedure (formula (7)). Consider

$$
\begin{aligned}
& \beta=\frac{2 w_{1}-w_{0}}{6 w_{1}-w_{0}-6 w_{2}}, \\
& \alpha=\frac{\left(w_{0}-2 w_{1}\right) \beta}{\Gamma(1+1 / \beta) \Gamma(1-1 / \beta)}, \\
& \gamma=w_{0}-\alpha \Gamma\left(1+\frac{1}{\beta}\right) \Gamma\left(1-\frac{1}{\beta}\right),
\end{aligned}
$$

where $\Gamma(1+1 / \beta)$ is the gamma function of $(1+1 / \beta), w_{s}$ is the probability-weighted moments (PWMs) of order $s$, and $s=0,1,2$ (formula (8)). Consider

$$
w_{s}=\frac{1}{n} \sum_{i=1}^{n}\left(1-\frac{j-0.35}{n}\right)^{s} D_{i},
$$

where $n$ is the number of data points and $j$ is the range of observations in increasing order.

Formula (9) gives the probability distribution function of the log-logistic distribution for $D$ series:

$$
F(x)=\left[1+\left(\frac{\alpha}{x-\gamma}\right)^{\beta}\right]^{-1}
$$

The SPEI value can be obtained as the standardized value of $F(x)$ with the following formula:

$$
\begin{array}{r}
\text { SPEI }=W-\frac{c_{0}+c_{1} W+c_{2} W^{2}}{1+d_{1} W+d_{2} W^{2}+d_{3} W^{3}}, \\
W=\sqrt{-2 \ln (P)} \text { for } P \leq 0.5,
\end{array}
$$

where $P$ is the probability of exceeding a determined $D$ value and $P=1-F(x)$; when $P>0.5, P=1-P$. And the constants are

$$
\begin{aligned}
& c_{0}=2.515517, \\
& c_{1}=0.802853, \\
& c_{2}=0.010328, \\
& d_{1}=1.432788, \\
& d_{2}=0.189269, \\
& d_{3}=0.001308 .
\end{aligned}
$$

The annual scale drought level was defined as five types and each standard of SPEI range was given in Table 1.

3.3. M-K Method. The Mann-Kendall method, a nonparameter method, was applied in this study to detect the drought mutation [22, 23]. On the basis of a stable meteorological sequence, for a time series $x$ with a sample size of $n$, a rank sequence was constructed as follows:

$$
d_{k}=\sum_{i=1}^{k} r_{i}, \quad(2 \leq k \leq n)
$$

where $r_{i}$ is the cumulative number of $x_{i}>x_{j}(1 \leq j \leq i)$.

The expectation $E\left(d_{k}\right)$ and variance $\operatorname{Var}\left(d_{k}\right)$ of $d_{k}$ are as follows:

$$
\begin{aligned}
E\left(d_{k}\right) & =\frac{k(k-1)}{4}, \\
\operatorname{Var}\left(d_{k}\right) & =\frac{k(k-1)(2 k+5)}{72},
\end{aligned}
$$

$$
(2 \leq k \leq n) \text {. }
$$

Under the hypothesis that the time series is random and independent, statistics $U F_{k}$ were defined as follows:

$$
U F_{k}=\frac{d_{k}-E\left(d_{k}\right)}{\sqrt{\operatorname{Var}\left(d_{k}\right)}}, \quad(k=1,2, \ldots, n) .
$$

Given the significance level of $\alpha=0.05\left(U_{0.05}= \pm 1.96\right)$, when $\left|U F_{k}\right|>U_{\alpha}$, the sequence has a significant increasing or decreasing trend. All of $U F_{k}$ points make up $U F$ curve. The antitone sequence $U B$ curve was drawn in the same way. If $U F>0$, the sequence shows an increasing trend and vice versa. When $U F$ exceeds the critical line, the sequence has a significant rising or dropping trend, and the exceeding ranges are considered as the mutation time zone. If the point where $U F$ curve cuts $U B$ curve is located between the two critical lines, the $x$-axis value of this point is the commencement of mutation. 


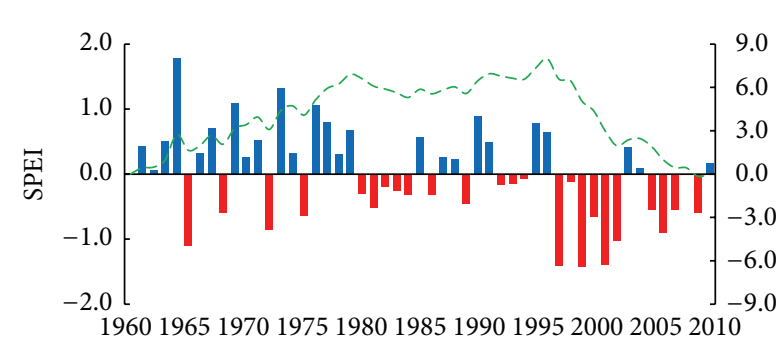

19601965197019751980198519901995200020052010

Year

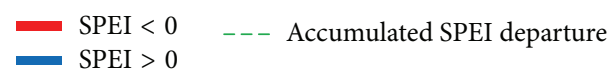

(a)

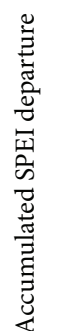

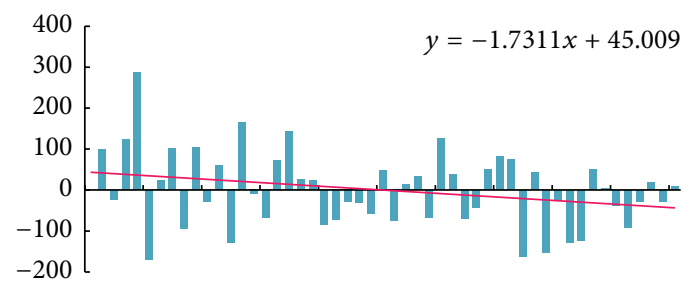

19601965197019751980198519901995200020052010

Year

Annual water deficit departure ( $\mathrm{mm})$

L Linear

FIGURE 2: The interannual variability of annual SPEI value (a) and annual water deficit (b).

\section{Results and Discussion}

4.1. The Interannual Variability of SPEI Value in Annual and Seasonal Scale. To obtain the overall SPEI value of HRB in regional scale, Thiessen polygon method was applied to diverge the annual and seasonal averaged SPEI value of each separated meteorological stations to the whole HRB. Figure 2(a) shows the interannual variability of the annual SPEI value and annual water deficit (P-PET) of HRB. Before 1995 , most of the annual SPEI values are positive with some years having a value more than 1.0; only the value of the year 1965 is less than -1.0; however, right after 1995, almost every SPEI value is negative; nearly half of them are less than -1.0 , except a few years with a SPEI value of just above 0 . The accumulated SPEI departure curve depicts that the annual SPEI increases from 1961, peaks at about 8.5 in 1995, and drops sharply until 2010. According to Table 1, the drought degree is negatively correlated with the SPEI value, which indicates that the annual drought in HRB, as shown in Figure 2(a), is becoming serious and frequent. The increasing-decreasing trend of accumulated SPEI departure shows the climate in HRB is changing from wet to dry especially after 1995. More clearly, from Figure 2(b), the annual water deficit in HRB shows a dropping trend with a gradient of -1.7311 , which means the difference between the precipitation and potential evapotranspiration is expanding.

Figures 3(a)-3(d) demonstrate the interannual variability of SPEI value and the accumulated SPEI departure in four seasons. From Figure 3(a) (left), before 1980, spring is experiencing a fluctuating climate change. During the 1980s, the SPEI in spring has an increasing trend, yet it turns out to be an opposite trend after 1990. Figures 3(b)-3(d) (right) show a similar changing trend of SPEI value in summer, autumn, and winter. Most of the early ages of the three seasons are dominated by humid climate, while after the early 1990s drought has become the main climate type in HRB. Figure 3 (right) shows the water deficit in four seasons, except for spring with an increasing trend of 0.7463 in gradient; summer, autumn, and winter show a correspondent dropping trend with gradients of $-2.1018,-0.3275$, and -0.2487 , separately. All in all, the variation trends of SPEI value and water deficit indicate that the drought frequency and degree in HRB are increasing from 1961 to 2010 both in annual scale and in seasonal scale, which is particularly significant after the early 1990s.

4.2. The Interannual Variability of Drought Area in Different Drought Levels. From the 5-year moving average of drought area in Figure 4, it shows that the drought area has an overall increasing trend during the last 50 years. The ratio of drought area to overall area fluctuates from 1961 to the early 1990s, while it rises sharply from 1994 and peaks in 1999 at just under $80 \%$; then the ratio has a dropping trend and ends up in $38 \%$. The increasing trend of drought is significant at 0.01 probability level, and the ascending gradient of ratio is $0.64 \% / a$. The continuous expanding of drought area in HRB would lead to a severer condition to the local water resources and exacerbate the water shortage in local agricultural irrigation.

Figures 5(a)-5(d) illustrate the variability of drought area percentage in four degrees. From the four pictures, the affecting areas of $\mathrm{HRB}$ of all degrees of drought show an increasing trend and the light and moderate drought are the main drought types that HRB face. From the 5-year moving average of the four types of drought, Figure 5(a) shows the light drought area has a fluctuant increasing trend from the area percentage of $10 \%$ in 1961 to $20 \%$ in 2010 , with an increasing slope of $0.18 \% / a$. Figure $5(\mathrm{~b})$ indicates the moderate drought area percentage decreases slightly from 1961 to 1994, while it surges sharply from 1994 and arrives at the culmination of $35 \%$ in 1999; then it declines to approximately $15 \%$ in 2010. The overall increasing gradient is $0.31 \% / a$. Figures 5 (c) and 5(d) demonstrate a similar changing trend; the influencing areas of severe and extreme drought are near 0 before 1994; however, both the ratio of severe drought area and the ratio of extreme drought area rise significantly from 1994 and peak at $20 \%$ and $1.5 \%$, respectively, in 1999 ; then they drop notably until 2005 at just above 0 . The overall increasing gradient is $0.14 \% / a$ and $0.1 \% / a$, separately. The increasing trends of light, moderate, and severe drought are significant at 0.01 probability level, while the increasing trend of extreme drought is significant at 0.05 probability level. The results show that all kinds of drought influencing area in HRB have been expanding during the last 50 years especially after the early 1990 s. 


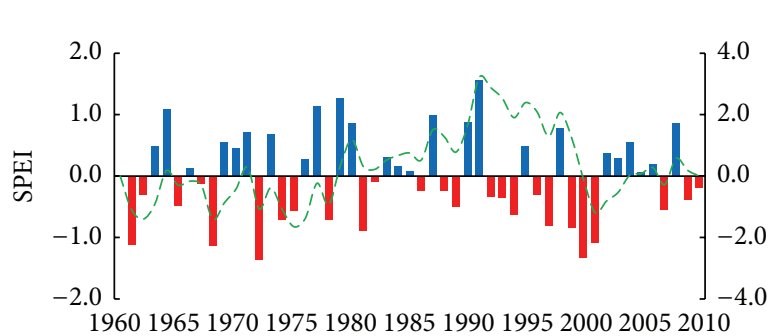

19601965197019751980198519901995200020052010 Year

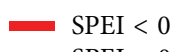

- - Accumulated SPEI departure

SPEI $>0$

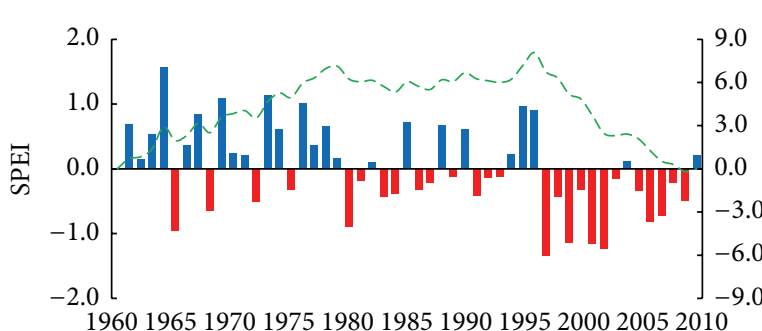

Year

SPEI $<0 \quad---$ Accumulated SPEI departure
SPEI $>0$

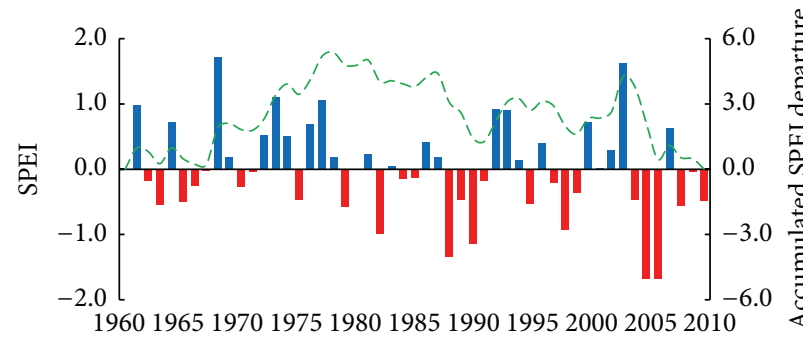
Year

SPEI $<0$

SPEI $>0$

- - - Accumulated SPEI departure

(c)

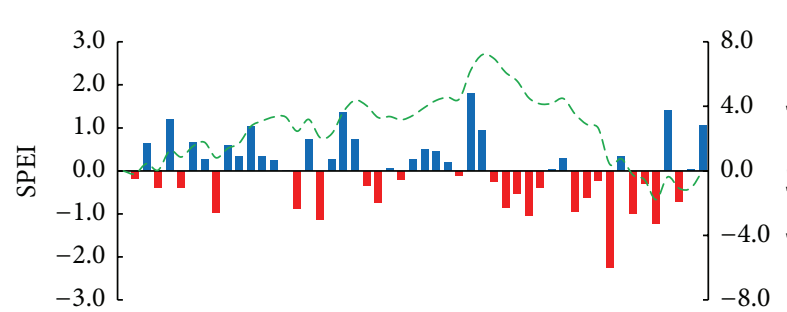

19601965197019751980198519901995200020052010

Year

SPEI $<0 \quad---$ Accumulated SPEI departure
SPEI $>0$

(d)

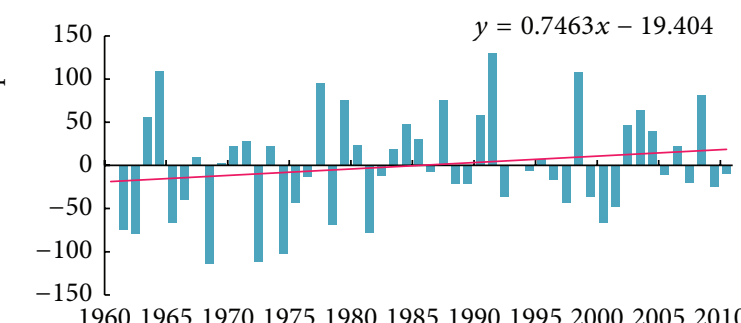

Year

Annual water deficit departure (mm) Linear

(a)

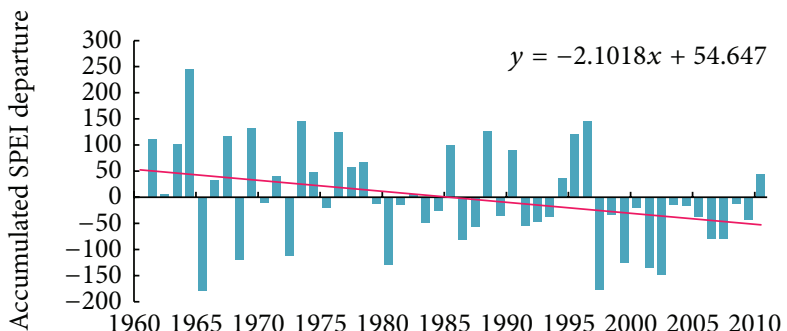

Year

Annual water deficit departure (mm)

L Linear

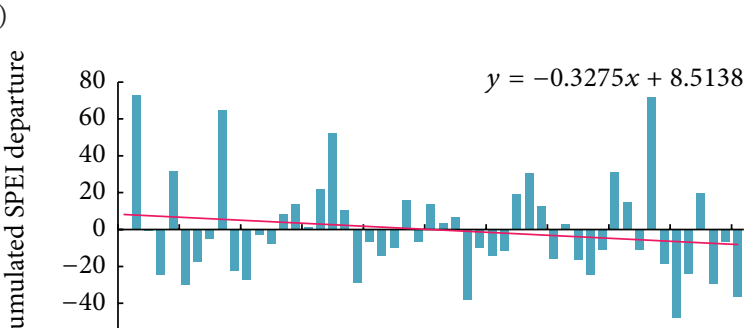

-60 L

19601965197019751980198519901995200020052010 Year

Annual water deficit departure (mm)

)

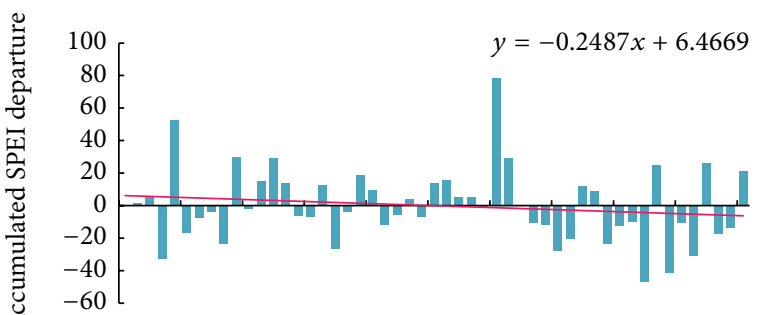

Year

Annual water deficit departure (mm)

Linear

FIGURE 3: The interannual variability of (a) spring, (b) summer, (c) autumn, and (d) winter SPEI value (left) and water deficit (right). 


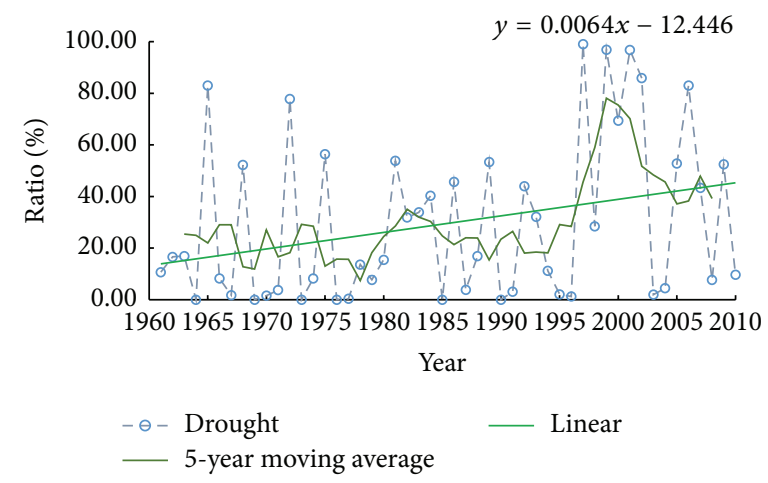

FIgURE 4: The interannual variability of drought area.

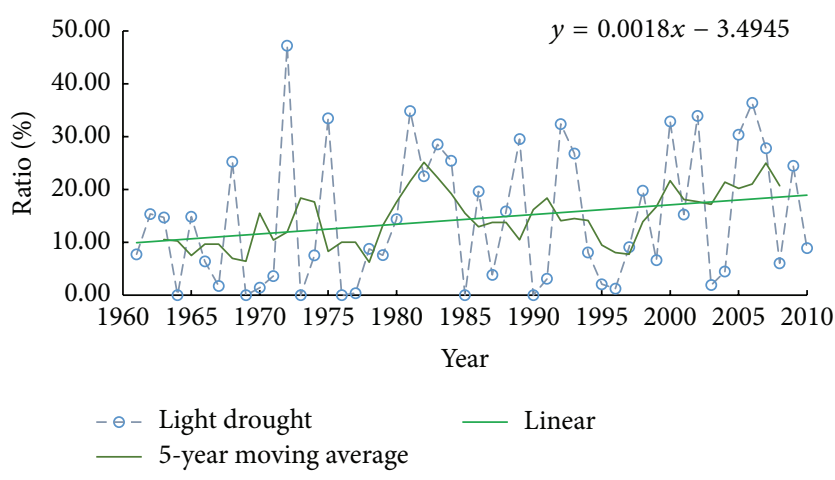

(a) Light drought

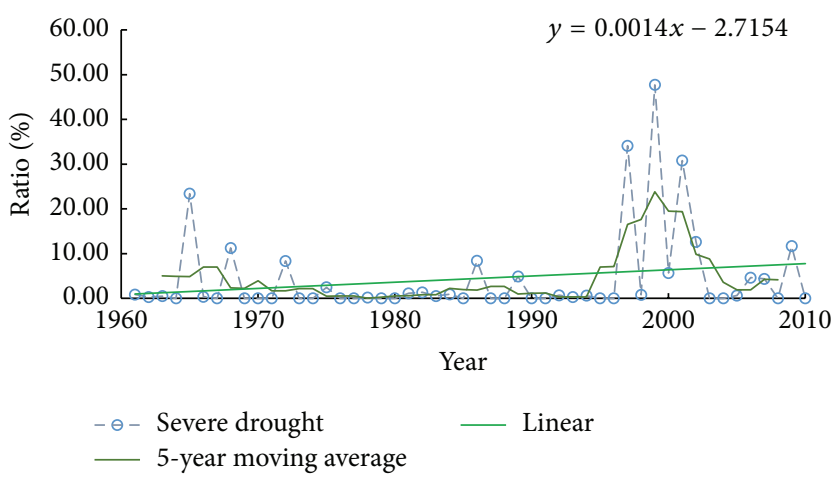

(c) Severe drought

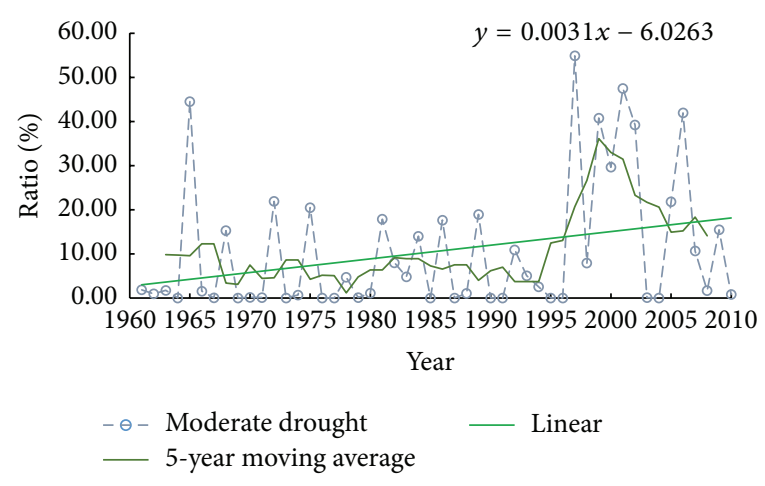

(b) Moderate drought

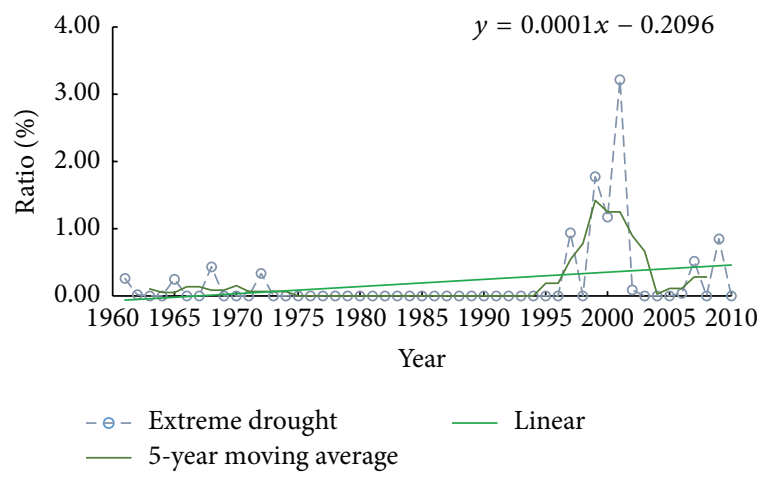

(d) Extreme drought

FIGURE 5: The interannual variability of drought area in four sublevels.

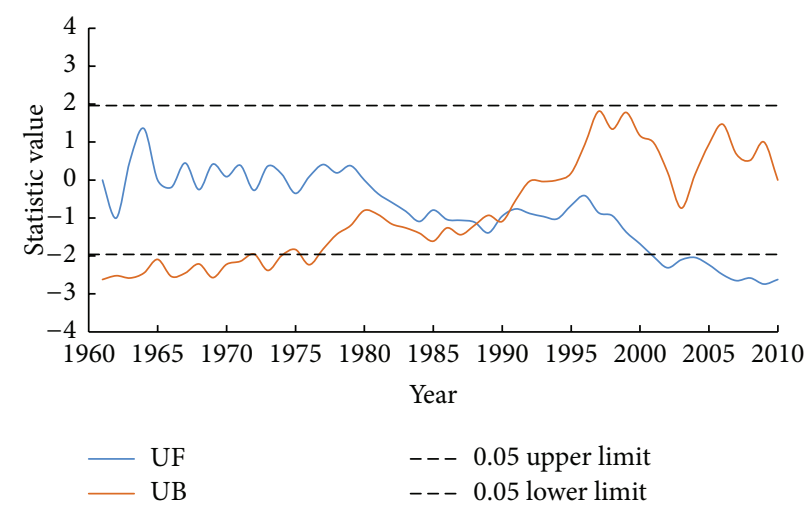

FIgURE 6: The result of M-K test. 


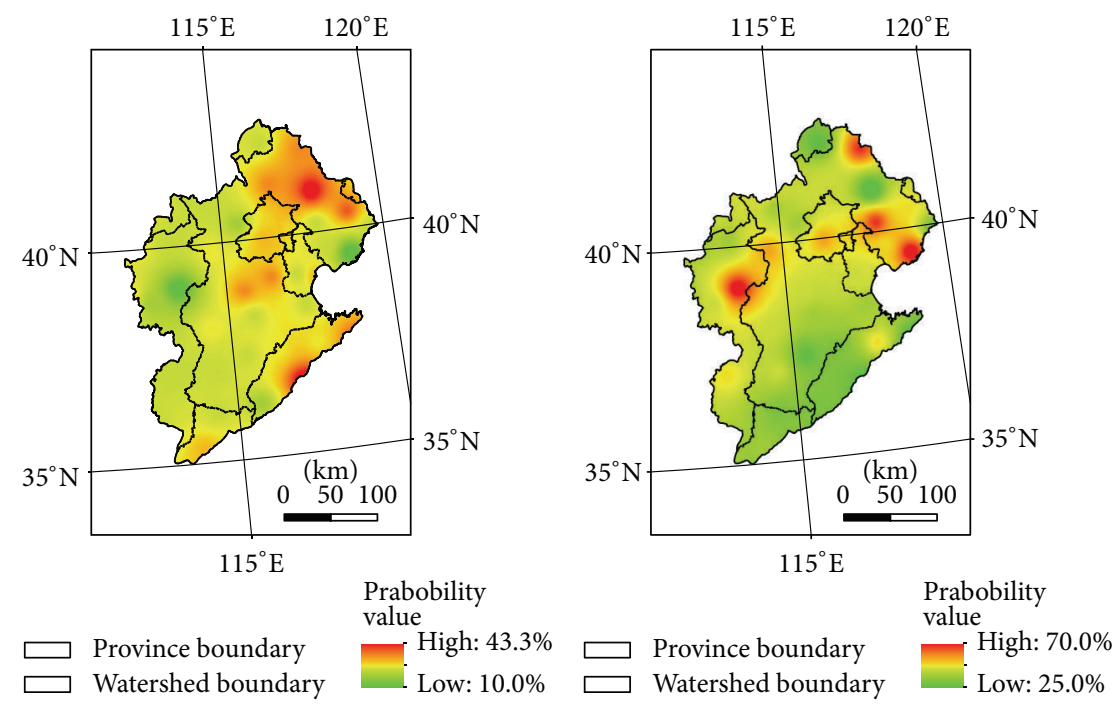

(a)

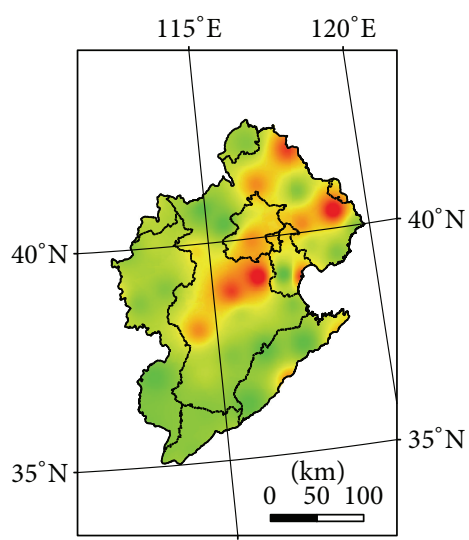

$115^{\circ} \mathrm{E}$

Prabobility

value

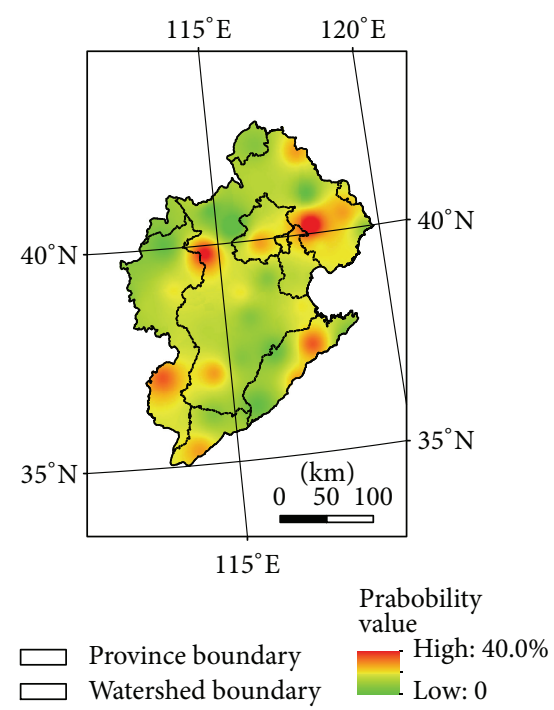

(b)
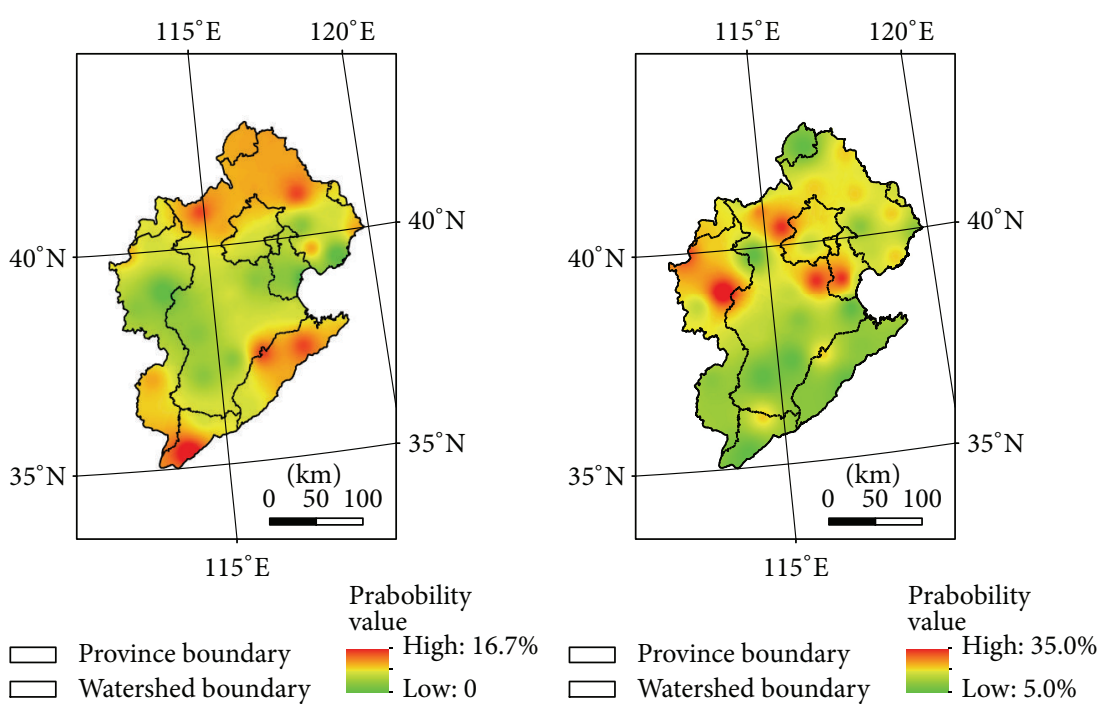

(c)

Figure 7: Continued. 

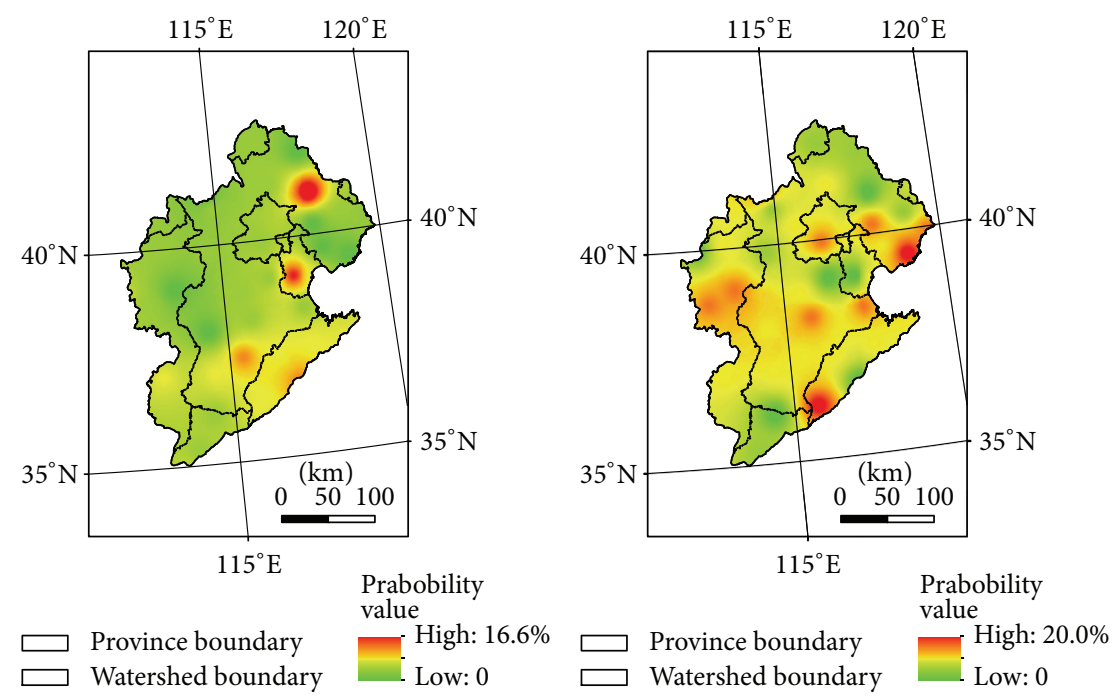

(d)
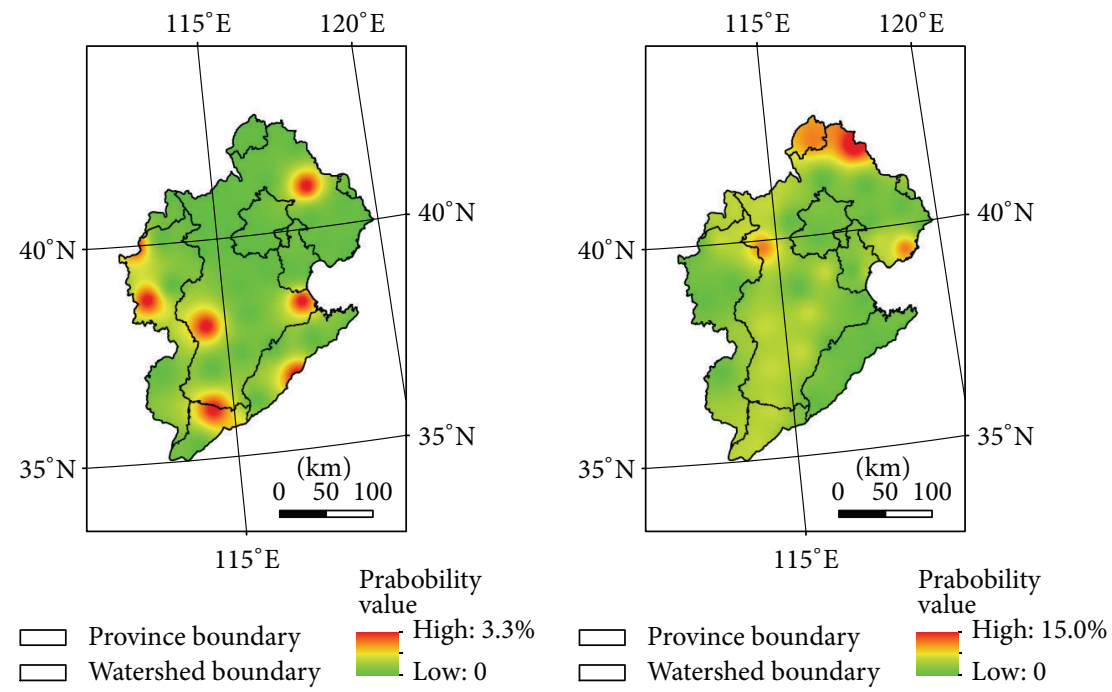

(e)

Figure 7: The comparison of spatial distribution of the occurrence probability of (a) drought, (b) light drought, (c) moderate drought, (d) severe drought, and (e) extreme drought between 1961 and 1990 (left) and between 1991 and 2010 (right).

4.3. M-K Test. As given in Figures 2-5, the climate in HRB has a significant change after the early 1990s; to further explore this phenomenon, $\mathrm{M}-\mathrm{K}$ method was applied to detect the mutation of the SPEI series. With a highly correspondent relationship with the temporal variability showing in Figures 2-5 that the drought happening frequency rises notably and that drought influencing area expands remarkably since the early 1990s, Figure 6 indicates the drought mutation happens in around 1990, which suggests that the climate in HRB changed acutely after 1990.

4.4. The Spatial Variability of Drought in Different Drought Levels. To further analyze the variability of spatial distribution of all degrees of drought, Inversed Distance Weight (IDW) method was used to interpolate the probability of different drought events classified by SPEI of 47 stations to HRB based on GIS in two time ranges, 1961-1990 and 1991-2010, divided by the mutation point. Figures $7(\mathrm{a})-7(\mathrm{e})$ show the comparison of all kinds of drought happening probability between the two time ranges. Figure 7 (left) illustrates that before 1990 drought happens most likely in the north HRB with a probability of $43.3 \%$; light drought occurs most probably in the center and northeast of HRB with a rate of $26.7 \%$; moderate drought mainly happens in the north Hebei province and west Shandong province, of which the happening rate is $16.7 \%$; the northeast Hebei province is the region where the severe drought occurs most frequently at a ratio of $16.6 \%$; extreme drought happens mostly in some separate part of the north HRB with a highest probability of $3.3 \%$.

Figure 7 (right) manifests that after 1990 places where drought happens most possibly are northeast Hebei province and east Shanxi province with a possibility up to $70 \%$; the 
major regions where light drought takes places are northeast and west Henan province with a feasibility of $40 \%$; moderate drought happens most frequently in the middle and west $\mathrm{HRB}$, of which the likelihood is $35 \%$; severe drought evenly distributes in HRB with a highest happening possibility of $20 \%$ in west Shandong province; extreme drought occurs intensively in north $\mathrm{HRB}$, which has an occurrence rate of $15 \%$. From the comparison in Figure 7, it can be drawn that drought and the subclass drought have a significant increasing occurrence trend after 1990. Meanwhile, there is a trend that places where all degrees of drought happen intensively are moving from north HRB to middle HRB.

\section{Conclusions}

This paper investigated the spatiotemporal drought variation patterns in HRB based on SPEI. The following important conclusions can be drawn from this study:

(1) The annual and seasonal drought in HRB is becoming serious and frequent for the last 50 years. In annual scale, the major climate character in HRB changed from wet to dry after 1995; in seasonal scale, most of the drought events happen after the early 1990s, especially in summer, autumn, and winter.

(2) From 1961 to 2010, the ratio of drought influencing area and all degrees of drought influencing area to HRB area have a dramatic rising trend, particularly the moderate drought with an increasing gradient of $0.31 \% / a$, and the overall drought affecting area increases $0.64 \%$ each year.

(3) There is a climate mutation which happened in 1990; after the mutation, the probability of all degrees of drought happening jumped to a comparatively high level; at the same time, the distribution of the intensive drought occurrence regions altered from north HRB to the middle of HRB, from mountainous area to arable land.

(4) The increasing drought happening rate, the expanding drought area, and the moving intensive drought occurrence center have been and would continue impeding the sustainable development of social economy in HRB leading to a severer negative impact on the agricultural production in the North China Plain.

\section{Conflict of Interests}

The authors declare that there is no conflict of interests regarding the publication of this paper.

\section{Acknowledgments}

This research was financially supported by National Key Technologies R\&D Program of China during 12th Five-Year Plan Period (no. 2012BAC19B03), Customized Research of National Environmental Public Welfare Industry "Impact of Climate Change on Water Environment Quality and Its
Adaptive Strategies" (no. 201509027), and the General Program of the National Natural Science Foundation of China (no. 51279207, no. 51409266, and no. 51522907).

\section{References}

[1] J. T. Chu, J. Xia, C. Y. Xu, L. Li, and Z. G. Wang, "Spatial and temporal variability of daily precipitation in Haihe River basin, 1958-2007," Journal of Geographical Sciences, vol. 20, no. 2, pp. 248-260, 2010.

[2] Q. J. Dong and X. Liu, "Risk assessment of water security in Haihe River Basin during drought periods based on D-S evidence theory," Water Science and Engineering, vol. 7, no. 2, pp. 119-132, 2014.

[3] R. G. Jiang, J. C. Xie, H. L. He, J. G. Luo, and J. W. Zhu, “Use of four drought indices for evaluating drought characteristics under climate change in Shaanxi, China: 1951-2012," Natural Hazards, vol. 75, no. 3, pp. 2885-2903, 2015.

[4] W. Wang, Y. Zhu, R. G. Xu, and J. T. Liu, "Drought severity change in China during 1961-2012 indicated by SPI and SPEI," Natural Hazards, vol. 75, no. 3, pp. 2437-2451, 2015.

[5] W. H. Nama, M. J. Hayes, M. D. Svoboda, T. Tadesse, and D. A. Wilhite, "Drought hazard assessment in the context of climate change for South Korea," Agricultural Water Management, vol. 160, pp. 106-117, 2015.

[6] B. Bonaccorso, I. Bordi, A. Cancelliere, G. Rossi, and A. Sutera, "Spatial variability of drought: an analysis of the SPI in Sicily," Water Resources Management, vol. 17, no. 4, pp. 273-296, 2003.

[7] G. Tsakiris and H. Vangelis, "Towards a drought watch system based on spatial SPI," Water Resources Management, vol. 18, no. 1, pp. 1-12, 2004.

[8] J. B. Li, F. H. Chen, E. R. Cook, X. H. Gou, and Y. X. Zhang, "Drought reconstruction for north central China from tree rings: the value of the Palmer drought severity index," International Journal of Climatology, vol. 27, no. 7, pp. 903-909, 2007.

[9] S. M. Vicente-Serrano, S. Beguería, and J. I. López-Moreno, "A multiscalar drought index sensitive to global warming: the standardized precipitation evapotranspiration index," Journal of Climate, vol. 23, no. 7, pp. 1696-1718, 2010.

[10] B. F. Sun, H. Zhao, and X. K. Wang, "Spatiotemporal characteristics of drought in northeast China based on SPEI," Ecology and Environmental Sciences, vol. 24, no. 1, pp. 22-28, 2015.

[11] D. Zhou, B. Zhang, J. Luo, C. Zhang, M. An, and D. Wang, "SPEI-based intensity characteristics and cause analysis of drought in north china during recent 50 years," Journal of Natural Disasters, vol. 23, no. 4, pp. 192-202, 2014.

[12] G. J. Xiong, B. K. Zhang, C. Y. Li, K. Z. Shang, and S. G. Wang, "Characteristics of drought variations in southwest China in 1961-2012 based on SPEI," Progressus Inquisitiones de Mutatione Climatis, vol. 9, no. 3, pp. 192-198, 2013.

[13] B. Gao, T. Jiang, B. D. Su, X. Y. Zhu, and Y. J. Wang, "Evolution analysis on droughts in northeast China during 1961-2012 based on SPEI," Chinese Journal of Agrometeorology, vol. 35, no. 6, pp. 656-662, 2014.

[14] S. Beguería, S. M. Vicente-Serrano, F. Reig, and B. Latorre, "Standardized precipitation evapotranspiration index (SPEI) revisited: parameter fitting, evapotranspiration models, tools, datasets and drought monitoring," International Journal of Climatology, vol. 34, no. 10, pp. 3001-3023, 2014.

[15] V. Potop, M. Možný, and J. Soukup, "Drought evolution at various time scales in the lowland regions and their impact on 
vegetable crops in the Czech Republic," Agricultural and Forest Meteorology, vol. 156, pp. 121-133, 2012.

[16] M. X. Yu, Q. F. Li, M. J. Hayes, M. D. Svoboda, and R. R. Heim, "Are droughts becoming more frequent or severe in China based on the standardized precipitation evapotranspiration index: 1951-2010?" International Journal of Climatology, vol. 34, no. 3, pp. 545-558, 2014.

[17] J. T. Chu, J. Xia, C. Y. Xu, and V. P. Singh, "Statistical downscaling of daily mean temperature, pan evaporation and precipitation for climate change scenarios in Haihe River, China," Theoretical and Applied Climatology, vol. 99, no. 1-2, pp. 149-161, 2010.

[18] Z. X. Bao, J. Y. Zhang, G. Q. Wang et al., "Attribution for decreasing streamflow of the Haihe River basin, northern China: climate variability or human activities?" Journal of Hydrology, vol. 460-461, no. 16, pp. 117-129, 2012.

[19] J. Li, Y. J. Yue, H. M. Pan, and X. Y. Ye, "Variation rules of meteorological drought in China during 1961-2010 based on SPEI and intensity analysis," Journal of Catastrophology, vol. 29, no. 4, pp. 176-182, 2014.

[20] B. Ming, Y. Q. Guo, H. B. Tao, G. Z. Liu, S. K. Li, and P. Wang, "SPEI ${ }_{P M}$-based research on drought impact on maize yield in North China Plain," Journal of Integrative Agriculture, vol. 14, no. 4, pp. 660-669, 2015.

[21] C. W. Thornthwaite, "An approach toward a rational classification of climate," Geographical Review, vol. 38, no. 1, pp. 55-94, 1948.

[22] K. H. Hamed, "Trend detection in hydrologic data: the MannKendall trend test under the scaling hypothesis," Journal of Hydrology, vol. 349, no. 3-4, pp. 350-363, 2008.

[23] Z. J. Li, X. B. Li, and Z. M. Xu, "Impacts of water conservancy and soil conservation measures on annual runoff in the Chaohe River Basin during 1961-2005," Journal of Geographical Sciences, vol. 20, no. 6, pp. 947-960, 2010. 

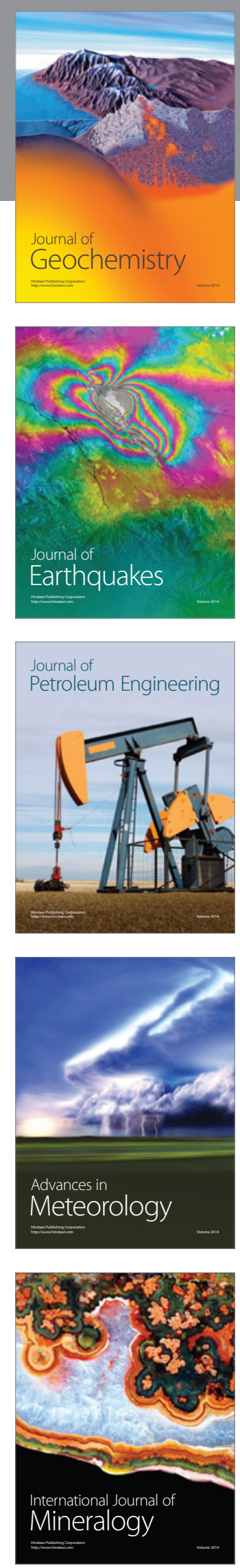
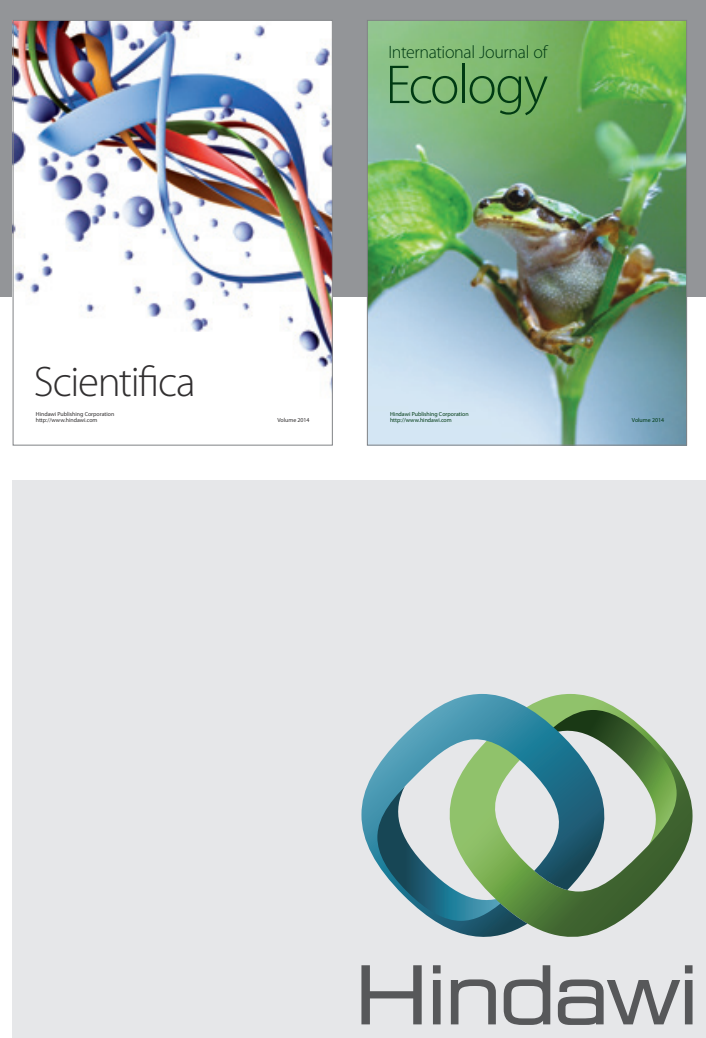

Submit your manuscripts at

http://www.hindawi.com
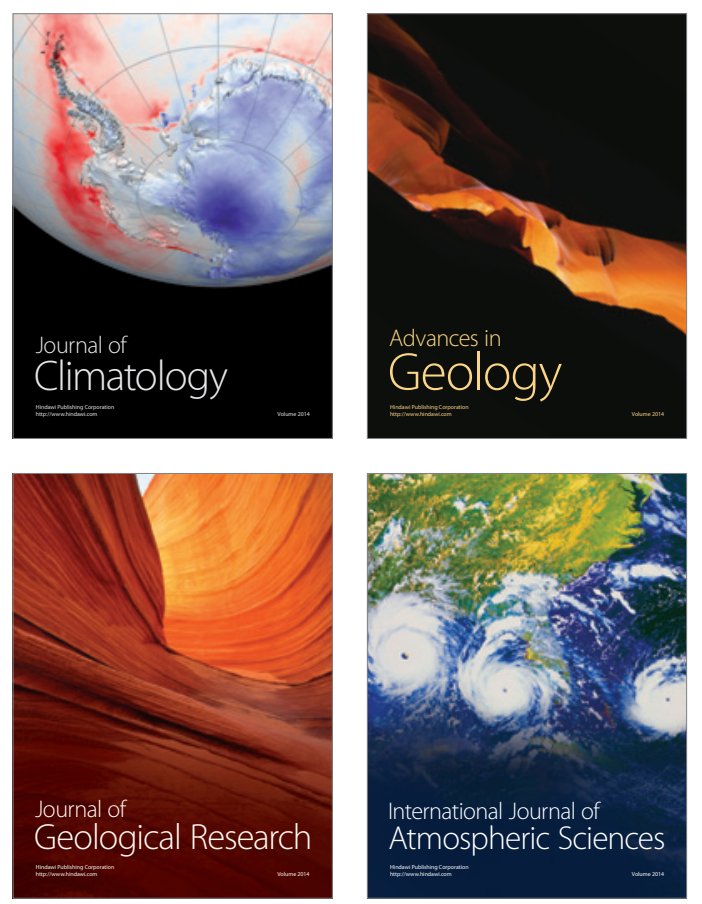

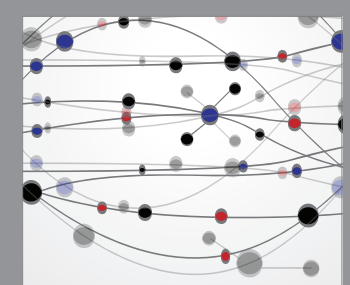

The Scientific

\section{World Journal}
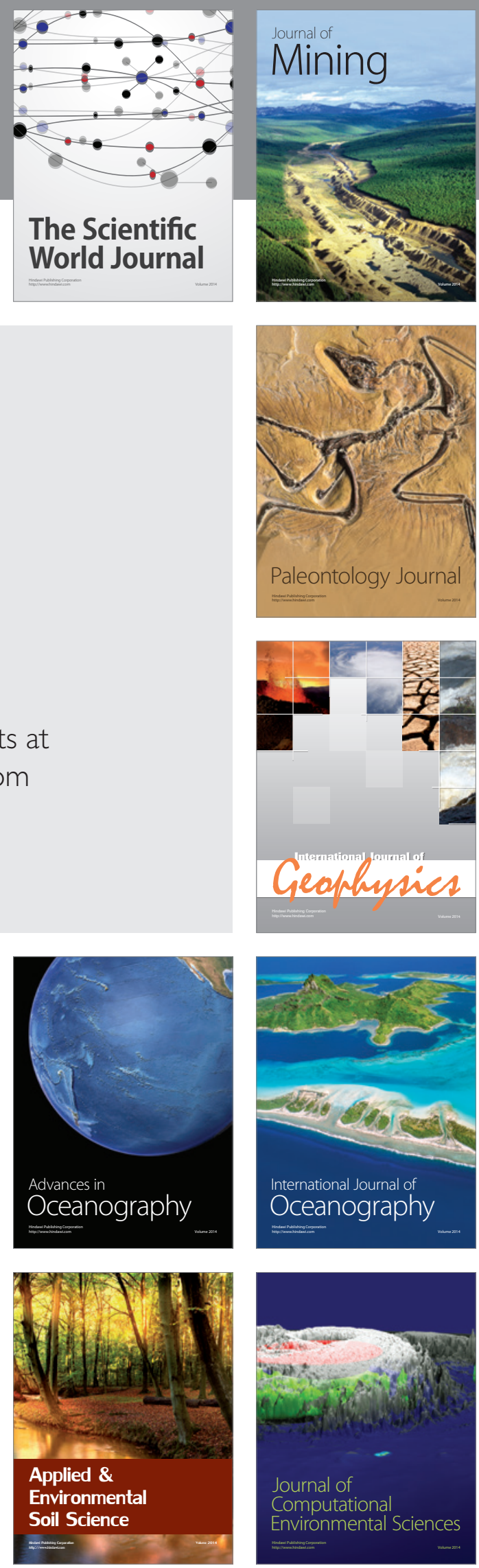